\title{
Modeling Pavement Performance Using LTPP Database for Flexible Pavements
}

\author{
Mostafa M. RADWAN ${ }^{1}$ \\ Mostafa A. ABO-HASHEMA ${ }^{2}$ \\ Moatafa D. HASHEM ${ }^{3}$ \\ Hamdy B. FAHEEM ${ }^{4}$
}

\begin{abstract}
In many countries, incredible investments have been made in constructing roads that require conducting periodic evaluation and timely maintenance and rehabilitation (M\&R) plan to keep the network operating under acceptable level of service. The timely M\&R plan necessitates accurately predicting pavement performance, which is an essential element of road infrastructure asset management systems or Pavement Management Systems (PMS). Consequently, there is always a need to develop and to update performance prediction models embedded in PMS applications. This study focuses on developing distress prediction models for flexible pavements located in non-freeze climatic zone, which represent most of the Middle East countries using data extracted from the Long-Term Pavement Performance (LTPP) program. Six distress performance prediction models were developed in this study for both wet- and dry-non-freeze climatic zones, which are Fatigue (Alligator) cracking, longitudinal cracking, transverse cracking, raveling, bleeding, and rut depth models. These models can play an important role assisting decision makers in predicting pavement performance, identifying M\&R needs, rational budget planning and resource allocation.
\end{abstract}

Keywords: Prediction models, distress models, ltpp, statistical modeling, flexible pavement, nonfreeze climatic zone.

Note:

- This paper has been received on October 31, 2018 and accepted for publication by the Editorial Board on April 22, 2019.

- Discussions on this paper will be accepted by September 30, 2020.

- https://dx.doi.org/10.18400/tekderg.476606

1 Nahda University, Faculty of Engineering, Beni Suef, Egypt - mostafa.yaseen@nub.edu.eg https://orcid.org/0000-0002-6246-1609

2 Fayoum University, Faculty of Engineering, Fayoum, Egypt - maa03@fayoum.edu.eg https://orcid.org/0000-0002-8301-0946

3 Minia University, Faculty of Engineering, Minia, Egypt - mostafa.deeb@mu.edu.eg https://orcid.org/0000-0001-8564-5550

4 Minia University, Faculty of Engineering, Minia, Egypt - hamdyfaheem@mu.edu.eg https://orcid.org/0000-0002-9841-6519 


\section{INTRODUCTION}

Road network represents the powerful engine of economy to all countries, which requires conducting periodic evaluation and timely maintenance and rehabilitation (M\&R) plan to keep the network operating under acceptable level of service $[1,2]$. The timely M\&R plan necessitates accurately predicting pavement performance, which is a key element of road Pavement Management Systems (PMS). The performance models calculate the future conditions of pavement based on which PMS optimizes several M\&R treatments and estimates the consequences of maintenance operations on the future pavement condition during the life-span of the pavement [3,4]. At the network level, pavement performance prediction is needed for programming M\&R activities, while at the project level it is needed for determining the most appropriate $M \& R$ actions to be taken for a specific project, such as preventive maintenance, rehabilitation, or reconstruction $[5,6]$.

Consequently, there is always a need to develop and to update performance prediction models embedded in PMS applications. Early PMSs did not have pavement performance curves rather they evaluated only the current pavement condition. Later, the simplified pavement performance curves were introduced based on the engineering opinions on the expected design life of different M\&R actions [7]. The only predictive variable of these performance curves was the pavement age. The development of pavement performance is explicitly complicated as the pavement performance is subjected to a large number of parameters of pavement performance. There are two streams of pavement performance modeling, which are deterministic and stochastic approaches. The major differences between deterministic and stochastic performance prediction models are model development concepts, modeling processor formulation, and output format of the models [8].

There are different types of deterministic models, such as mechanistic models, mechanisticempirical models, and regression models. The mechanistic models draw the relationship between response parameters such as stress, strain, and deflection [8]. The mechanisticempirical models are often developed in connection to design systems and therefore have not been widely applied in PMS but have the potential to be applied at a network level. On the other hand, the regression models draw the relationship between a performance parameter (e.g., pavement distresses) and the predictive parameters (e.g., pavement thickness, pavement material properties, traffic loading, and age) $[8,9]$.

This study focuses on developing regression models through deterministic approach to predict pavement performance. These prediction models allow highway authorities to predict the pavement performance and consequently identifying the M\&R timely activities. Several performance prediction models have been introduced over the years, some of which are simple and others are quite complex. Many of these models are developed for application in a particular region or country under specific traffic and climatic conditions; hence, they cannot be directly applied in other countries or conditions. Therefore, this study comes to target specific climate condition. Table 1 shows selected published pavement distress models.

Hence, this study comes to develop pavement distress prediction models for roads located in wet- and dry-non-freeze climatic zones, which represent most of the Middle East countries using data extracted from the Long-Term Pavement Performance (LTPP) program. Therefore, the developed models can be utilized in the Middle East region experiencing the same climatic condition. This study is considered as a crucial attempt to develop such models 
for the Middle East region due to lack of resources led to unavailability of such models in most of the Middle East countries. However, calibration of the developed models is recommended using local pavement performance data, whenever performance data is available.

Table 1 - Selected Pavement Distress Prediction Models

\begin{tabular}{|c|c|c|}
\hline Model Formula & Abbreviations & Reference \\
\hline $\mathrm{RD}=\sum_{\mathrm{i}=1}^{\text {Nsublayers }} \varepsilon_{\mathrm{p}}^{\mathrm{i}} \mathrm{h}_{\mathrm{i}}$ & $\begin{array}{l}\mathrm{RD}=\text { Rut Depth }, \mathrm{mm} \\
\varepsilon_{\mathrm{p}}^{\mathrm{i}}=\text { plastic strain } \\
\mathrm{h}_{\mathrm{i}}=\text { layer thickness, } \mathrm{mm}\end{array}$ & $\begin{array}{l}\text { ARA, } \\
2004[10]\end{array}$ \\
\hline $\begin{array}{l}\operatorname{Ln~RD~}_{\text {dry }}=0.681+0.114(\text { Ln KESAL })+ \\
0.007\left(\mathrm{D}>32 \mathrm{C}^{\circ}\right)\end{array}$ & $\begin{array}{l}\text { KESAL }=\text { Standard Traffic Axle loads, } \\
\text { thousands } \\
D>32 C^{\circ}=\text { Number of days maximum } \\
\text { temperature }>32 \mathrm{C}^{\circ}\end{array}$ & $\begin{array}{l}\text { Naiel, } \\
2010[6]\end{array}$ \\
\hline $\begin{array}{l}\mathrm{Ln} \mathrm{RD}_{\text {wet }}=0.9+0.19(\mathrm{AC} \%)-0.077 \\
(\mathrm{SN})+0.063(\mathrm{Ln} \text { KESAL })\end{array}$ & $\begin{array}{l}\mathrm{RD}=\text { Rut Depth }, \mathrm{mm} \\
\mathrm{SN}=\mathrm{Structural} \text { Number } \\
\text { KESAL = No. of Standard Traffic Axle } \\
\text { loads }\end{array}$ & $\begin{array}{l}\text { Naiel, } \\
2010[6]\end{array}$ \\
\hline $\mathrm{N}_{100}^{\text {rut }}=\frac{1}{0.9533 \times \text { rut }^{-0.0209}} \times\left(\frac{\text { rut }}{a}\right)^{\frac{1}{b}}$ & $\begin{array}{l}\mathrm{Nrut}_{100}=\text { the average annual ESALs per } \\
\text { lane } \\
\text { rut }=\text { the total rutting on the surface } \\
\text { used to define failure, mm. } \\
\mathrm{a}, \mathrm{b}=\text { parameters estimated from FWD } \\
\text { test as the surface curvature index } \\
\mathrm{SCI} 300 \text { in }[\mu \mathrm{m} \text { ] measured during the } \\
\text { fall (autumn), first time after the } \\
\text { pavement structure is built. }\end{array}$ & $\begin{array}{l}\text { Göransson } \\
\text { and Den } \\
\text { Svenska, } \\
2009[11]\end{array}$ \\
\hline $\begin{array}{l}\mathrm{Nf}=0.00432 \times \beta \mathrm{f} 1 \times \mathrm{C} \\
\mathrm{x}\left(\frac{1}{\varepsilon_{t}}\right)^{3.291 \times \beta \mathrm{f} 2}\left(\frac{1}{\mathrm{E}}\right)^{0.854 \times \beta \mathrm{f} 3}\end{array}$ & $\begin{array}{l}\mathrm{Nf}=\text { the maximum allowable number } \\
\text { of repetitions } \\
\beta \mathrm{f} 1, \beta \mathrm{f} 2, \beta \mathrm{f} 3=\text { calibration factors } \\
\mathrm{C}=\text { laboratory to field adjustment } \\
\text { factor } \\
\varepsilon_{\mathrm{t}}=\text { critical tensile strain } \\
\mathrm{E}=\text { the stiffness of the } \mathrm{AC} \text { surface layer }\end{array}$ & $\begin{array}{l}\text { AI, } 1982 \\
{[12]}\end{array}$ \\
\hline$\%$ Fatigue cracking $=\frac{0.021}{0.027+\mathrm{e}^{(-0.851 \times \mathrm{Df})}}$ & $\begin{array}{l}\mathrm{FC}=\text { fatigue cracking in percent of } \\
\text { entire lane area, }(\%) . \\
\mathrm{Df}=\text { cumulative fatigue damage }\end{array}$ & $\begin{array}{l}\text { Ali and } \\
\text { Tayabii, } \\
1989[13]\end{array}$ \\
\hline $\begin{array}{l}(\mathrm{FC}) \mathrm{wet}=\exp (-6.539+0.078 \times \text { age }+ \\
0.00187 \times \mathrm{KESAL}+0.000673 \times \text { precip }+ \\
0.0914 \times \text { temp }+15097 \times \text { epsilon.t }+ \\
0.0272 \times \mathrm{ft})\end{array}$ & $\begin{array}{l}\mathrm{FC}=\text { fatigue cracking in percent of } \\
\text { entire lane area, }(\%) \\
\text { age }=\text { pavement age, years. } \\
\mathrm{KESAL}=\text { the yearly ESALs, } \\
\text { thousands. } \\
\text { precip = mean annual precipitation, } \\
\mathrm{mm} . \\
\text { temp = mean annual temperature, }{ }^{\circ} \mathrm{C} \\
\text { epsilon.t = the critical tensile strain. } \\
\mathrm{ft}=\text { yearly freeze-thaw cycle }\end{array}$ & $\begin{array}{l}\text { Ker et al., } \\
2007[14]\end{array}$ \\
\hline
\end{tabular}


Table 1 - Selected Pavement Distress Prediction Models (continue)

\begin{tabular}{|c|c|c|}
\hline Model Formula & Abbreviations & Reference \\
\hline $\begin{array}{l}(\mathrm{FC}) \mathrm{dry}=\exp (-48.411+0.119 \text { age }+0.025 \\
\mathrm{x} \text { precip }+1.774 \mathrm{x} \text { temp }+2729 \mathrm{x} \text { epsilon.t } \\
+0.0272 \mathrm{x} \mathrm{ft})\end{array}$ & $\begin{array}{l}\mathrm{FC}=\text { fatigue cracking in percent of } \\
\text { entire lane area, }(\%) \\
\text { epsilon.t = the critical tensile strain. } \\
\mathrm{ft}=\text { yearly freeze-thaw cycle }\end{array}$ & $\begin{array}{l}\text { Ker et al., } \\
2007 \text { [14] }\end{array}$ \\
\hline $\begin{array}{l}(\mathrm{FC}) \text { freeze }=\exp (-5.944+0.00583 \mathrm{x} \\
\text { precip }+41.768 \times \text { epsilon.t }-0.002 \times \text { visco } \\
+0.4 \times \text { trange })\end{array}$ & $\begin{array}{l}\text { Visco = viscosity of the AC layer, } \mathrm{p} . \\
\text { trange }=\text { the difference of maximum } \\
\text { and minimum mean annual } \\
\text { temperature, }{ }^{\circ} \mathrm{C}\end{array}$ & $\begin{array}{l}\text { Ker et al., } \\
2007 \text { [14] }\end{array}$ \\
\hline $\begin{array}{l}(\mathrm{FC}) \text { nonfreeze }=\exp (-7.87+0.102 \times \text { age } \\
+0.00219 \times \mathrm{KESAL}+0.00102 \times \text { precip }+ \\
0.0472 \times \text { temp }+15172 \times \text { epsilon } \mathrm{t}+ \\
0.0476 \times \mathrm{ft})\end{array}$ & $\begin{array}{l}\mathrm{FC}=\text { fatigue cracking in percent of } \\
\text { entire lane area, }(\%) \\
\text { epsilon.t }=\text { the critical tensile strain. } \\
\mathrm{ft}=\text { yearly freeze-thaw cycle }\end{array}$ & $\begin{array}{l}\text { Ker et al., } \\
2007 \text { [14] }\end{array}$ \\
\hline
\end{tabular}

Such models would help highway authorities, located in non-freeze climatic zones, to precisely predict pavement performance and hence using these predictions in identifying the M\&R activities. Based on the data available in the LTPP, six distress prediction models were developed in this study, for both wet- and dry-non-freeze climatic zones, as follows:

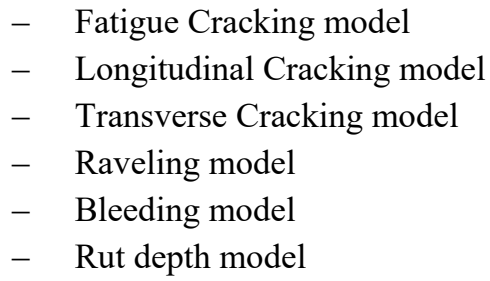

The precision and accuracy of the distress prediction models are affected by the type of the mathematical model. Therefore, a comprehensive statistical analysis should be performed to get a model with high accuracy. A stepwise regression analysis was conducted to come up with the most effective factors that could affect such models. Consequently, a Statistical Package for Social Science (SPSS) program was used to develop such models. To check the reliability of the model, some measures of the statistical accuracy are used as follows $[15$, 16]:

- The Standard Error (SE), which is a measure of the statistical accuracy of an estimate,

- The coefficient of determination $\left(\mathrm{R}^{2}\right)$, which is defined as the proportion of the variance in the dependent variable that is predictable from the independent variable(s).

In statistics, normality tests are used to determine if a data set is well-modeled by a normal distribution and to compute how likely it is for a random variable underlying the data set to be normally distributed. If the data is normally distributed, analysis of variance (ANOVA) test is used. However, Kruskal-Wallis or Mann-Whitney tests is used for non-normal data. 


\section{BACKGROUND OF LTPP}

The Long-Term Pavement Performance program (LTPP) is the largest pavement performance research program ever undertaken, gathering data from more than 2,000 pavement test sections over a 20 -year test period. The single most significant product of the LTPP program is the pavement database - the largest and most comprehensive collection of research-quality performance data on in-service highway pavements ever assembled.

The Long-Term Pavement Performance program is one of the significant research regions of the Strategic Highway Research Program (SHRP). The initial five years of the LTPP program were finished under the subsidizing and course of SHRP. Since 1991, the Federal Highway Administration (FHWA) has proceeded with the administration and subsidizing of the program. The LTPP program is overseen by the LTPP Team under the Office of Infrastructure Research and Development [17, 18, 19].

The LTPP program has two complementary experiments to meet the objectives. First, the General Pavement Studies (GPS) use existing pavements as originally constructed or after the first overlay and focus on the most commonly used structural designs for pavement. The second set of LTPP experiments is the Specific Pavement Studies (SPS) whose test sections allow critical design factors to be controlled and performance to be monitored from the initial date of construction. The results will provide a better understanding of how selected maintenance, rehabilitation, and design factors affect pavement performance. The consolidated GPS and SPS programs comprise of more than 2,500 test segments situated on all through North America built in four climate zones: wet-non-freeze, dry-non-freeze, wetfreeze, and dry-freeze. The LTPP program screens and gathers asphalt execution information on every single dynamic site. The gathered information incorporates data on seven modules: Inventory, Maintenance, Monitoring (Deflection, Distress, and Profile), Rehabilitation, Materials Testing, Traffic, and Climatic. The LTPP Information Management System (IMS) is the focal database where every one of the information gathered under the LTPP program are put away. This database is persistently being produced as more information is gathered and handled $[17,18]$.

\section{OBJECTIVE AND METHODOLOGY}

The main objective of this study is to develop pavement distress prediction models for flexible pavements located in wet- and dry-non-freeze climatic zones, which represent most of the Middle East countries using LTPP database. This study focuses on developing such models for the Middle East countries experiencing wet- and dry-non-freeze climatic zones, to be used in their PMS; while calibration of the developed models is recommended based on local condition of a country whenever the pavement performance data is available.

Therefore, four main steps were conducted to achieve the objective of this study. Data collection and preparation using LTPP database was the first main step. The second step was statistical analysis that came to play the role of judgment on all possible factors that could affect developing such models as well as their significance. Developing and optimizing the pavement distress prediction models using SPSS software were the third step. The validation process was the last essential step. 


\section{DATA COLLECTION AND PREPARATION}

The LTPP dataset was the main source of data in this study, which includes data until year 2016. Therefore, LTPP sites, located in wet- and dry-non-freeze climatic zones, were selected to obtain the required data according to specific criteria as follows:

- Sites located in wet- and dry-non-freeze climatic zones.

- Only overlaid sections were chosen to simulate newly constructed pavement.

- Rural sections were selected to represent main roads.

- Design period or data range was selected for 25 years, starting from 1991.

Accordingly, 43 and 57 LTPP sites were selected for wet- and dry-non-freeze climatic zones, respectively. Data collection step was then started. There are numerous factors related to the occurrence of the pavement problems. However, this study selected some factors that are considered as the most important factors related to pavement problems especially for fatigue cracking, longitudinal cracking, transverse cracking, raveling distress, bleeding distress, and rutting distress. These factors are summarized as follows:

- $\quad$ Air temperature $(\mathrm{Ta}),{ }^{\circ} \mathrm{C}$

- Pavement age since overlay (PA), years

- Traffic loading represented by Equivalent Single Axle Load (ESAL), No. of Axles

- Annual Precipitation, mm

- Available pavement distresses, area (sq.m.) or length (m)

- Asphalt pavement thickness (T), mm

- Material characteristics:

- $\quad$ Resilient modulus of subgrade soil (Mr), MPa

- $\%$ Passing the \#200 sieve $(0.075 \mathrm{~mm})$ of subgrade soil $\left(\mathrm{P}_{200}\right)$,

- $\%$ Air voids of asphalt mix $\left(\mathrm{V}_{\mathrm{a}}\right)$,

- $\%$ Asphalt content in the mix $\left(\mathrm{P}_{\mathrm{b}}\right)$

- $\%$ Moisture content of base/subbase courses $\left(\mathrm{MC}_{\mathrm{b}}\right)$,

- $\%$ Moisture content of subgrade soil $\left(\mathrm{MC}_{\mathrm{S}}\right)$, and

- Plasticity index of subgrade soil (PI)

All data were collected on different dates during the 25-year data range. The collected data have been filtered through a screening process to come up with feasible data that could be used to develop the required models. The criteria for screening process are selected as follows:

1. Unavailability and/or insufficient of some distresses data

2. Absence of material characteristics data

3. Abnormal data patterns, e.g. distress density should be increased with time not decreased. 
Table 2 - Selected Non-Freeze LTPP Sites

\begin{tabular}{|c|c|c|c|}
\hline Site ID & State & Site ID & State \\
\hline \multicolumn{4}{|c|}{ Wet-Non-Freeze Climatic Zone } \\
\hline $12-3997$ & Florida (FL) & $28-2807$ & Mississippi (MS) \\
\hline $12-3996$ & Florida (FL) & $28-3081$ & Mississippi (MS) \\
\hline $12-4106$ & Florida (FL) & $37-1024$ & North Carolina (NC) \\
\hline $12-4107$ & Florida (FL) & $37-1030$ & North Carolina (NC) \\
\hline $12-4108$ & Florida (FL) & $37-1802$ & North Carolina (NC) \\
\hline $12-4097$ & Florida (FL) & $40-1017$ & Oklahoma (OK) \\
\hline $12-9054$ & Florida (FL) & $40-4163$ & Oklahoma (OK) \\
\hline $13-4096$ & Georgia (GA) & $40-4087$ & Oklahoma (OK) \\
\hline $13-4112$ & Georgia (GA) & $40-4161$ & Oklahoma (OK) \\
\hline $13-4113$ & Georgia (GA) & $40-4165$ & Oklahoma (OK) \\
\hline $13-4111$ & Georgia (GA) & $45-1025$ & South Carolina (SC) \\
\hline $13-4420$ & Georgia (GA) & $5-3048$ & Arkansas \\
\hline $1-1021$ & Alabama (AL) & 48-3729 & Texas (TX) \\
\hline $1-4126$ & Alabama (AL) & 48-1113 & Texas (TX) \\
\hline $1-4129$ & Alabama (AL) & 48-1116 & Texas (TX) \\
\hline $1-1001$ & Alabama (AL) & 48-1093 & Texas (TX) \\
\hline $1-1019$ & Alabama (AL) & $48-1068$ & Texas (TX) \\
\hline 24-1632 & Maryland (MD) & $48-1060$ & Texas (TX) \\
\hline $28-1001$ & Mississippi (MS) & $48-3609$ & Texas (TX) \\
\hline $28-3028$ & Mississippi (MS) & $51-1023$ & Virginia (VA) \\
\hline 28-3091 & Mississippi (MS) & $51-2021$ & Virginia (VA) \\
\hline \multicolumn{4}{|c|}{ Dry-Non-Freeze Climatic Zone } \\
\hline $4-1002$ & Arizona (AZ) & 35-0108 & New Mexico (NM) \\
\hline $4-1003$ & Arizona (AZ) & $35-0103$ & New Mexico (NM) \\
\hline $4-1006$ & Arizona (AZ) & 35-0104 & New Mexico (NM) \\
\hline $4-1007$ & Arizona (AZ) & $35-0106$ & New Mexico (NM) \\
\hline $4-1015$ & Arizona (AZ) & $35-0105$ & New Mexico (NM) \\
\hline $4-1017$ & Arizona (AZ) & $35-1112$ & New Mexico (NM) \\
\hline $4-1021$ & Arizona (AZ) & $35-0107$ & New Mexico (NM) \\
\hline $4-1024$ & Arizona (AZ) & $35-0109$ & New Mexico (NM) \\
\hline $4-1025$ & Arizona (AZ) & $35-0110$ & New Mexico (NM) \\
\hline 4-0113 & Arizona (AZ) & $35-0112$ & New Mexico (NM) \\
\hline $4-1062$ & Arizona (AZ) & 35-0101 & New Mexico (NM) \\
\hline $4-0160$ & Arizona (AZ) & $48-1111$ & Texas (TX) \\
\hline $4-1065$ & Arizona (AZ) & $48-1061$ & Texas (TX) \\
\hline $4-6055$ & Arizona (AZ) & $48-1076$ & Texas (TX) \\
\hline $6-8151$ & California (CA) & $48-3769$ & Texas (TX) \\
\hline $6-2004$ & California (CA) & $48-6060$ & Texas (TX) \\
\hline $35-0101$ & New Mexico (NM) & 48-1048 & Texas (TX) \\
\hline
\end{tabular}

Sites to be selected for validation process 
Consequently, 42 LTPP sites out of 43 were selected for wet-non-freeze climatic zone; and 34 LTPP sites out of 57 were selected for dry-non-freeze climatic zone, as shown in Table 2. Furthermore, fatigue cracking, longitudinal cracking, transverse cracking, raveling distress, bleeding distress, and rutting distress were selected for model development. The unit of distress data recorded in the LTPP database is based on the distress types. The unit of area is accounted for fatigue, raveling, and bleeding; on the other hand, the unit of length or depth is accounted for longitudinal, transverse, and rutting distress. In addition to the collected distress data, distress density was calculated by dividing the length or area of distress by the area of examined section based on the PAVER system [20].

Comprehensive database was then created to be used for model development and validation process. The database was split into two categories of dataset. The first category is for model development, which represents $79 \%$ of all databases, and the second category is for validation process, which represents $21 \%$ of all database, as shown in Table 2 . The validation data of $21 \%$ is considered reasonable statistically and the validation sites were selected to represent most of the original data and most of the sites. It is noteworthy that the developed models should not be exposed to the validation dataset while developing the models.

\section{DEVELOPMENT OF PAVEMENT DISTRESS PREDICTION MODELS}

This part deals with the process of developing fatigue cracking, longitudinal cracking, transverse cracking, raveling distress, bleeding distress, and rutting distress models. Since ESAL is a function of time or age, either ESAL or age would be selected as independent variable in the developed models. Sample of collected data is shown in Table 3 and Table 4 for wet- and dry-non-freeze climatic zones, respectively, for different LTPP sites shown in Table 2.

Table 3 - Sample of Collected Data using Wet-Non-Freeze LTPP Sites for Different LTPP Sites

\% Ta, PA, Mr, $\quad \mathbf{P}_{200}$

$\begin{array}{lll}\text { \%Density } & \text { Ta, } & \text { PA, } \\ \text { C }^{0} & \text { Years }\end{array}$

\section{Fatigue Cracking Model}

$\begin{array}{ccc}0 & 24.30 & 4 \\ 6.67 & 19.40 & 14 \\ 16.67 & 21.90 & 16.16\end{array}$

Longitudinal Cracking Model

$\begin{array}{ccc}0 & 24.29 & 4 \\ 0.05 & 19.29 & 5.83 \\ 17.0 & 18 & 6.42\end{array}$

Transverse Cracking Model

$\begin{array}{ccc}0 & 20.00 & 0.18 \\ 0.7624 & 16.40 & 4.52 \\ 7.8756 & 20.30 & 7.02\end{array}$

\section{7}

95
$\% \mathrm{Va}$

$\% \mathrm{MC}_{\mathrm{b}}$

$\% M C_{S}$

PI
(\%)

9.40

4
4
3

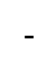

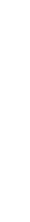


Table 3 - Sample of Collected Data using Wet-Non-Freeze LTPP Sites for Different LTPP Sites (continue)

$\begin{array}{ccccccccc}\% \text { Density } & \text { Ta, } & \text { PA, } & \text { Mr, } & \text { P }_{200} & \% V a & \% C_{b} & \% M C s & \text { PI }\end{array}$

\section{Raveling Model}

\begin{tabular}{ccccccccc}
0 & 13.50 & 0.12 & 20 & 25.40 & 4.593 & 4 & 18 & 12 \\
12.5041 & 19.40 & 4.7 & 73 & 3.50 & 6.993 & 4 & 7 & 2 \\
36.9383 & 24.30 & 13 & - & - & - & - & 5 & - \\
\hline
\end{tabular}

\section{Rutting Model}

\begin{tabular}{cccccc}
$\begin{array}{c}\text { Rut Depth } \\
\text { mm }\end{array}$ & $\begin{array}{c}\text { Ta, } \\
\mathrm{C}^{\mathrm{o}}\end{array}$ & PA, Years & ESAL & $\begin{array}{c}\text { Annual } \\
\text { Precipitation, } \\
\text { mm }\end{array}$ & $\% \mathrm{Va}$ \\
\hline 6 & 15.89 & 5.92 & 711 & 1778.5 & 7.091 \\
8 & 16.89 & 15.3 & 59 & 1679.30 & 5.823 \\
10 & 15.60 & 12 & 40 & 1290.30 & 7.09 \\
15 & 19.79 & 9.66 & 106 & 1418.59 & 3.993
\end{tabular}

Table 4 - Sample of Collected Data using Dry-Non-Freeze LTPP Sites for Different LTPP Sites

$\begin{array}{lccccccccc}\% \text { Density } & \text { Ta, } & \text { CA, Years } & \begin{array}{c}\text { Mr, } \\ \text { MPa }\end{array} & \begin{array}{c}\mathbf{P}_{200} \\ (\%)\end{array} & \% \text { Va } & \begin{array}{c}\text { T, } \\ \text { mm }\end{array} & \% \mathrm{MC}_{\mathrm{b}} & \% \mathrm{MC} & \text { PI }\end{array}$

\section{Fatigue Cracking Model}

$\begin{array}{cccccccccc}11.8 & 17.6 & 15.5 & 87 & - & - & 221 & 5 & 11 & 30 \\ 36.67 & 19.1 & 15.58 & 37 & - & - & 53.3 & 3 & 7 & 0 \\ 37.7 & 18.5 & 17.41 & 114 & - & - & 63.5 & 2 & 9 & 9\end{array}$

\section{Longitudinal Cracking Model}

2.84

15.5

6.45

16

8.17

17.1

\section{Transverse Cracking Model}

0

2.84

4.18

Bleeding Model

$\begin{array}{cccccccccc}0 & - & 1.2 & 45 & 24.9 & 1.87 & - & 3 & - & 6 \\ 7.21 & - & 8.21 & 105.5 & 28.5 & 3.62 & - & 2 & - & 0 \\ 27.37 & - & 12.58 & 75 & 9.6 & 12 & - & 1 & - & -\end{array}$


Table 4 - Sample of Collected Data using Dry-Non-Freeze LTPP Sites for Different LTPP Sites (continue)

\section{$\underline{\text { Rutting Model }}$}

\begin{tabular}{cccccc}
$\begin{array}{c}\text { Rut Depth } \\
\mathrm{mm}\end{array}$ & $\begin{array}{c}\text { Ta, } \\
\mathrm{C}^{\mathrm{o}}\end{array}$ & PA, Years & ESAL & $\begin{array}{c}\text { Annual } \\
\text { Precipitation, } \\
\mathrm{mm}\end{array}$ & $\% \mathrm{Va}$ \\
\hline 4 & 16.10 & 8.416 & 12 & 294.6 & 6.12 \\
5 & 17.70 & 15.5 & 4 & 343.4 & 6.12 \\
7 & 23.10 & 16.58 & 768 & 41 & 16.3 \\
11 & 22.70 & 18.25 & 925 & 121.9 & 16.3
\end{tabular}

\subsection{Stepwise Regression Test}

Stepwise regression test was performed within $95 \%$ confidence interval to come up with the most effective factors that could affect fatigue cracking, longitudinal cracking, transverse cracking, raveling distress, bleeding distress, and rutting distress. The decision would be made based on $p$-value for all considered factors. A small p-value (typically $\leq 0.05$ ) indicates strong evidence against the null hypothesis, so the null hypothesis is rejected. A large p-value $(>0.05)$ indicates weak evidence against the null hypothesis, so fail to reject the null hypothesis [21]. Table 5 and Table 6 depict the results of p-value of the considered factors for wet- and dry-non-freeze climatic zones, respectively.

Table 5 - P-value using Wet-Non-Freeze LTPP Sites

\begin{tabular}{lccccc}
\cline { 2 - 6 } & $\begin{array}{c}\text { Fatigue } \\
\text { Cracking }\end{array}$ & $\begin{array}{c}\text { Longitudinal } \\
\text { Cracking }\end{array}$ & $\begin{array}{c}\text { Transverse } \\
\text { Cracking }\end{array}$ & $\begin{array}{c}\text { Raveling } \\
\text { Distress }\end{array}$ & $\begin{array}{c}\text { Rut } \\
\text { Depth }\end{array}$ \\
\hline $\mathrm{Ta}$ & 0.54337 & 0.42071 & 0.97183 & 0.27308 & 0.46982 \\
$\mathrm{PA}$ & $\underline{\mathbf{0 . 0 1 4 4 7}}$ & 0.89778 & 0.52564 & $\underline{\mathbf{0 . 0 3 8 6 0}}$ & nil \\
$\mathrm{ESA}$ & & & & & $\underline{\mathbf{0 . 0 2 7 6 2}}$ \\
$\mathrm{L}$ & nil & nil & nil & nil & \\
$\mathrm{Mr}$ & 0.66094 & $\underline{\mathbf{0 . 0 3 4 7 3}}$ & 0.49485 & 0.88260 & 0.79112 \\
$\mathrm{P}_{200}$ & 0.66620 & 0.14896 & 0.95062 & 0.30984 & - \\
$\mathrm{Va}$ & 0.87726 & 0.14831 & nil & $\underline{\mathbf{0 . 0 1 4 2 7}}$ & $\underline{\mathbf{0 . 0 5 5 5 8}}$ \\
$\mathrm{T}$ & 0.98640 & 0.28561 & nil & nil & 0.90004 \\
$\mathrm{MC}$ & 0.79172 & $\underline{\mathbf{0 . 0 0 1 9 4}}$ & $\underline{\mathbf{0 . 0 3 1 6 5}}$ & 0.66059 & nil \\
$\mathrm{MCs}$ & $\underline{\mathbf{0 . 0 0 9 6 0}}$ & 0.61107 & 0.10406 & 0.24776 & nil \\
$\mathrm{PI}$ & 0.57023 & 0.26024 & $\underline{\mathbf{0 . 0 4 0 5 5}}$ & 0.12184 & nil \\
$\mathrm{Pb}_{\mathrm{b}}$ & nil & nil & nil & nil & nil \\
\hline
\end{tabular}

nil means that this factor is not considered in testing 
As shown in Table 5, fatigue cracking model is affected by pavement age and moisture content of subgrade soil for wet-non-freeze climatic zone. On the other hand, pavement age, air temperature, and plasticity index of subgrade soil are the factors that affect fatigue cracking model for dry-non-freeze climatic zone, as shown in Table 6. It could be concluded that moisture condition-related factors of subgrade soil affect the occurrence of fatigue cracking.

On the other hand, longitudinal cracking model is affected by resilient modulus of subgrade soil and moisture content of base/subbase courses for wet-non-freeze climatic zone while pavement age and \% passing the \#200 sieve $(0.075 \mathrm{~mm})$ of subgrade soil are the factors affecting longitudinal cracking model for dry-non-freeze climatic zone. It could be concluded that too much fine aggregate experiences this type of crack.

Table 6 - p-value using Dry-Non-Freeze LTPP Sites

\begin{tabular}{lccccc}
\cline { 2 - 5 } & $\begin{array}{c}\text { Fatigue } \\
\text { Cracking }\end{array}$ & $\begin{array}{c}\text { Longitudinal } \\
\text { Cracking }\end{array}$ & $\begin{array}{c}\text { Transverse } \\
\text { Cracking }\end{array}$ & $\begin{array}{c}\text { Bleeding } \\
\text { Distress }\end{array}$ & $\begin{array}{c}\text { Rut } \\
\text { Depth }\end{array}$ \\
\cline { 2 - 6 } Ta & $\underline{\mathbf{0 . 0 0 7 4 0}}$ & nil & nil & nil & $\underline{\mathbf{0 . 0 0 1 1 1}}$ \\
PA & $\underline{\mathbf{0 . 0 1 5 1 5}}$ & $\underline{\mathbf{0 . 0 0 0 0 0}}$ & $\underline{\mathbf{0 . 0 0 3 5 1}}$ & $\underline{\mathbf{0 . 0 0 0 0 3}}$ & nil \\
ESA & nil & nil & nil & nil & \\
L & & nil & & & $\underline{\mathbf{0 . 0 0 0 1 0}}$ \\
Mr & 0.43891 & $\underline{\mathbf{0 . 0 1 8 9 6}}$ & 0.14276 & 0.93685 & 0.14071 \\
$\mathrm{P}_{200}$ & nil & nil & nil & $\underline{\mathbf{0 . 0 1 8 3 2}}$ & $\underline{\mathbf{0 . 0 0 0 0 0}}$ \\
Va & nil & nil & nil & nil & nil \\
T & 0.38696 & 0.66000 & 0.82018 & 0.17165 & nil \\
MC & 0.28823 & nil & nil & nil & nil \\
MCs & 0.17819 & 0.75348 & 0.26137 & 0.22060 & nil \\
PI & $\underline{\mathbf{0 . 0 1 6 4 6}}$ & nil & nil & nil & 0.53185 \\
\hline$P_{b}$ & nil & & & &
\end{tabular}

nil means that this factor is not considered in testing

For transverse cracking model, it is affected by moisture content of base/subbase courses and plasticity index of subgrade soil for wet-non-freeze climatic zone while pavement age is the only factor affecting transverse cracking model for dry-non-freeze climatic zone.

Raveling and bleeding distress models are affected by pavement age and \% air voids of asphalt mix for wet- and dry-non-freeze climatic zones, respectively. Finally, rut depth is affected by ESAL and Va for wet-non-freeze climatic zone. On the other hand, ESAL, Ta and $\mathrm{V}_{\mathrm{a}}$ are the factors that affect rut depth for dry-non-freeze climatic zone. 


\subsection{Regression Analysis}

Multiple regression analysis technique was applied to develop fatigue cracking, longitudinal cracking, transverse cracking, raveling distress, bleeding distress and rut depth prediction models for wet- and dry-non-freeze climatic zones using SPSS software. Several trials were made to develop the required models that best represent the relation between the distresses with related factors. Table 7 shows regression analysis for developed models using nonfreeze LTPP sites.

Table 7 - Regression Analysis for Developed Models using Non-Freeze LTPP Sites

\begin{tabular}{|c|c|c|c|c|c|c|c|c|c|}
\hline \multirow{2}{*}{$\begin{array}{l}\text { Distress } \\
\text { Model }\end{array}$} & \multirow{2}{*}{ Climate } & \multirow{2}{*}{ Estimate } & \multicolumn{4}{|c|}{ Parameters } & \multirow{2}{*}{$\mathrm{R}^{2}$} & \multirow{2}{*}{$\mathrm{df}$} & \multirow{2}{*}{$\begin{array}{l}\text { Mean } \\
\text { Squares }\end{array}$} \\
\hline & & & A & B & $\mathrm{C}$ & $\mathrm{D}$ & & & \\
\hline \multirow{4}{*}{$\begin{array}{l}\text { Fatigue } \\
\text { Cracking }\end{array}$} & \multirow{2}{*}{ Wet } & Value & -10.356 & 1.936 & 1.422 & - & \multirow{2}{*}{0.884} & \multirow{2}{*}{3} & \multirow{2}{*}{488.633} \\
\hline & & SE & 2.263 & 0.359 & 0.251 & - & & & \\
\hline & \multirow{2}{*}{ Dry } & Value & -45.281 & 9.260 & 2.101 & 6.135 & \multirow{2}{*}{0.465} & \multirow{2}{*}{4} & \multirow{2}{*}{482.729} \\
\hline & & SE & 120.087 & 20.856 & 8.318 & 4.457 & & & \\
\hline \multirow{4}{*}{$\begin{array}{c}\text { Longitudinal } \\
\text { Cracking }\end{array}$} & \multirow{2}{*}{ Wet } & Value & 14.201 & -5.320 & 0.365 & - & \multirow{2}{*}{0.318} & \multirow{2}{*}{3} & \multirow{2}{*}{7.152} \\
\hline & & SE & 116.202 & 38.766 & 0.698 & - & & & \\
\hline & \multirow[t]{2}{*}{ Dry } & Value & 24.258 & 22.118 & $\begin{array}{c}- \\
0.078\end{array}$ & - & \multirow[t]{2}{*}{0.478} & \multirow[t]{2}{*}{4} & \multirow{2}{*}{31.956} \\
\hline & & SE & 7.389 & 0.109 & 7.385 & - & & & \\
\hline \multirow{4}{*}{$\begin{array}{l}\text { Transverse } \\
\text { Cracking }\end{array}$} & \multirow[t]{2}{*}{ Wet } & Value & -10.725 & 1.146 & $\begin{array}{c}- \\
9.164\end{array}$ & - & \multirow[t]{2}{*}{0.980} & \multirow[t]{2}{*}{3} & \multirow[t]{2}{*}{0.072} \\
\hline & & SE & 1.851 & 0.188 & 1.873 & - & & & \\
\hline & \multirow{2}{*}{ Dry } & Value & 0.048 & 0.203 & - & - & \multirow{2}{*}{0.755} & \multirow{2}{*}{1} & 120012 \\
\hline & & SE & 0.147 & 0.11 & - & - & & & $420.01 J$ \\
\hline Reveling & Wet & Value & -2.075 & -0.902 & 0.823 & - & 0323 & 3 & 19273 \\
\hline Distress & & SE & 1.924 & 1.037 & 0.468 & - & & & \\
\hline Bleeding & Dry & Value & 4.708 & 1.042 & 1.203 & - & 0820 & 3 & 1588807 \\
\hline Distress & & SE & 8.933 & 0.283 & 0.299 & - & & & \\
\hline & Wet & Value & 10.097 & -0.987 & 0.478 & - & 0233 & 3 & 603294 \\
\hline Rut & & $\mathrm{SE}$ & 2.664 & 0.474 & 0.229 & & & & \\
\hline Depth & Drv & Value & 21.338 & 0.009 & 1055 & 0.255 & 0.470 & 5 & 111000 \\
\hline & (Biy & SE & 0.317 & 0.210 & 4.384 & 0.002 & $0.4 / 9$ & J & 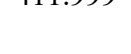 \\
\hline
\end{tabular}




\subsubsection{Fatigue Cracking Model}

Table 7 indicates that the model has $\mathrm{R}^{2}$ value of 0.884 and 0.465 based on the obtained data from LTPP for wet- and dry-non-freeze climatic zones, respectively. Therefore, the proposed distress model of fatigue cracking could be written as follows:

\section{Wet-non-freeze zone:}

$\%$ Fatigue Cracking $=e^{\left(-10.356+1.936 \sqrt{P A}+1.422 \sqrt{M C_{S}}\right)}$

Dry-non-freeze zone:

$\%$ Fatigue Cracking $=e^{(-45.28+9.26 \sqrt{P A}+2.1 \sqrt{P I})}+6.14 \cos T a$

\subsubsection{Longitudinal Cracking Model}

Table 7 indicates that the model has $\mathrm{R}^{2}$ value of 0.318 and 0.478 based on the obtained data from LTPP for wet- and dry-non-freeze climatic zones, respectively. Therefore, the proposed distress model of longitudinal cracking could be written as follows:

\section{Wet no-freeze zone:}

$\%$ Longitudinal Cracking $=e^{\left(-22.896-0.185 \log M C_{b}-28.073 \sqrt{M r}\right)}$

Dry no-freeze zone:

$\%$ Longitudinal Cracking $=24.258+22.118 \sin \sqrt{P A}-0.078 P_{200}$

\subsubsection{Transverse Cracking Model}

Table 7 indicates that the model has $\mathrm{R}^{2}$ value of 0.980 and 0.755 based on the obtained data from LTPP for wet- and dry-non-freeze climatic zones, respectively. Therefore, the proposed distress model of transverse cracking could be written as follows:

Wet no-freeze zone:

$\%$ Transerve Cracking $=e^{\left(-10+1.146 \sin P I-9.164 \cos M C_{b}\right)}$

Dry no-freeze zone:

$\%$ Transverse Cracking $=0.048+0.203 P A$

\subsubsection{Raveling Distress Model}

Table 7 indicates that the model has $\mathrm{R}^{2}$ value of 0.323 based on the obtained data from LTPP for wet-non-freeze climatic zones. Therefore, the proposed distress model of raveling distress could be written as follows:

Wet no-freeze zone:

$\%$ Raveling $=-2.075-0.902 \sin P A+0.823 \mathrm{Va}$ 


\subsubsection{Bleeding Distress Model}

Table 7 indicates that the model has $\mathrm{R}^{2}$ value of 0.820 based on the obtained data from LTPP for dry-non-freeze climatic zones. Therefore, the proposed distress model of bleeding distress could be written as follows:

Dry no-freeze zone:

$\%$ Bleeding $=4.708+1.043 P A+1.203 V_{a}$

\subsubsection{Rut Depth Model}

Table 7 indicates that the model has $\mathrm{R}^{2}$ value of 0.233 and 0.479 based on the obtained data from LTPP for wet- and dry-non-freeze climatic zones, respectively. Therefore, the proposed rut depth model could be written as follows:

\section{Wet no-freeze zone:}

Rut Depth $=10.097-0.987 \operatorname{Ln}(E S A L)+0.478 V_{a}$

Dry no-freeze zone:

Rut depth $=21.39+0.009 E S A L-1.05 T a+0.255 V_{a}$

\section{VALIDATION PROCESS}

Once the models were developed, validation process should start using LTPP data sets different from the database used in the development process. The second category of dataset was used for validation process, which represents $21 \%$ of entire database.

Predicted values were calculated using the developed models; however, the actual or measured values were obtained from the selected LTPP sites. Table 8 and Table 9 show the results of measured and predicted values of fatigue, longitudinal, transversal, raveling, bleeding and rutting for wet- and dry-non-freeze climatic zones, respectively. The results indicate that the predicted values are fairly close to the measured values at the corresponding LTPP sites.

Table 8 - Measured and Predicted Distress Density for Wet-Non-Freeze LTPP Sites

\begin{tabular}{|c|c|c|c|c|c|c|c|c|c|}
\hline \multicolumn{2}{|c|}{$\begin{array}{l}\% \text { Fatigue } \\
\text { Cracking }\end{array}$} & \multicolumn{2}{|c|}{$\begin{array}{l}\text { \%Longitudinal } \\
\text { Cracking }\end{array}$} & \multicolumn{2}{|c|}{$\begin{array}{c}\text { \% Transverse } \\
\text { Cracking }\end{array}$} & \multicolumn{2}{|c|}{$\%$ Raveling } & \multicolumn{2}{|c|}{$\begin{array}{c}\text { Rut } \\
\text { Depth, mm }\end{array}$} \\
\hline $\mathrm{M}$ & $\mathrm{P}$ & M & $\mathrm{P}$ & $\mathrm{M}$ & $\mathrm{P}$ & M & $\mathrm{P}$ & M & $\mathrm{P}$ \\
\hline 0.00 & 0.01 & 0.00 & 0.23 & 0.10 & 0.0531 & 0.14 & 0.74 & 4 & 4.77 \\
\hline 0.59 & 0.39 & 0.00 & 0.00 & 0.00 & 0.3756 & 0.00 & 0.63 & 12 & 12.09 \\
\hline 7.46 & 8.29 & 0.00 & 0.00 & 0.00 & 0.00 & 9.83 & 6.81 & 6 & 8.56 \\
\hline 0.00 & 0.04 & 2.18 & 1.27 & 0.00 & 0.00 & 0.35 & 0.59 & 7 & 9.43 \\
\hline 0.00 & 0.05 & 0.00 & 0.00 & 0.00 & 0.10 & 0.00 & 0.00 & 17 & 13.71 \\
\hline
\end{tabular}


Table 8 - Measured and Predicted Distress Density for Wet-Non-Freeze LTPP Sites (continue)

\begin{tabular}{|c|c|c|c|c|c|c|c|c|c|}
\hline \multicolumn{2}{|c|}{$\begin{array}{l}\% \text { Fatigue } \\
\text { Cracking }\end{array}$} & \multicolumn{2}{|c|}{$\begin{array}{l}\text { \%Longitudinal } \\
\text { Cracking }\end{array}$} & \multicolumn{2}{|c|}{$\begin{array}{l}\text { \% Transverse } \\
\text { Cracking }\end{array}$} & \multicolumn{2}{|c|}{$\%$ Raveling } & \multicolumn{2}{|c|}{$\begin{array}{c}\text { Rut } \\
\text { Depth, mm }\end{array}$} \\
\hline 2.23 & 1.64 & 0.00 & 0.00 & 0.00 & 0.02 & 0.00 & 0.00 & 12 & 10.54 \\
\hline 1.79 & 2.48 & 0.00 & 0.005 & 3.34 & 0.06 & 0.00 & 0.00 & 9 & 8.01 \\
\hline 20.56 & 24.35 & 0.00 & 0.00 & 6.82 & 0.01 & 0.00 & 0.00 & 6 & 5.29 \\
\hline 0.00 & 0.02 & 0.00 & 0.00 & 0.00 & 0.00 & 0.00 & 0.00 & 5 & 4.19 \\
\hline 13.32 & 9.54 & 13.52 & 1.03 & 0.41 & 0.40 & 0.00 & 2.4 & 6 & 5.06 \\
\hline 0.00 & 4.12 & 0.134 & .006 & 0.30 & 0.40 & 2.45 & 3.17 & 12 & 13.71 \\
\hline
\end{tabular}

Table 9 - Measured and Predicted Distress Density for Dry-Non-Freeze LTPP Sites

\begin{tabular}{cc|cc|cc|cc|cc}
\multicolumn{2}{c|}{ \%Fatigue } & \multicolumn{2}{c|}{ \%Longitudinal } & \multicolumn{2}{c|}{ \%Transverse } & \multicolumn{2}{c|}{ \%Bleeding } & \multicolumn{2}{c}{ Rut } \\
M racking & \multicolumn{2}{c|}{ Cracking } & \multicolumn{2}{c}{ Cracking } & \multicolumn{2}{c}{ Depth, mm } \\
4.18 & 4.35 & $\mathrm{M}$ & $\mathrm{P}$ & $\mathrm{M}$ & $\mathrm{P}$ & $\mathrm{M}$ & $\mathrm{P}$ & $\mathrm{M}$ & $\mathrm{P}$ \\
3.60 & 4.11 & 8.17 & 8.01 & 3.14 & 5.41 & 2.21 & 2.01 & 3 & 5.16 \\
5.78 & 4.99 & 11.31 & 10.52 & 2.34 & 3.92 & 5.32 & 6.15 & 7 & 6.42 \\
5.08 & 5.24 & 3.34 & 3.10 & 4.01 & 5.68 & 0.14 & 0.17 & 6 & 6.06 \\
4.58 & 5.94 & 4.48 & 3.75 & 3.65 & 6.08 & 24.63 & 28.61 & 7 & 7.30 \\
4.18 & 5.06 & 7.66 & 7.02 & 3.78 & 5.48 & 2.25 & 2.58 & 8 & 5.91 \\
4.32 & 4.89 & 6.45 & 6.44 & 6.89 & 9.28 & 4.31 & 4.92 & 7 & 5.93 \\
4.87 & 3.38 & 11.02 & 11.46 & 4.52 & 6.61 & 13.14 & 11.46 & 6 & 5.95 \\
5.44 & 4.85 & 3.64 & 3.21 & 8.44 & 9.98 & 0.15 & .16 & 5 & 5.31 \\
3.88 & 3.76 & 6.87 & 6.21 & 4.85 & 6.73 & 15.41 & 15.64 & 6 & 6.64 \\
4.02 & 4.92 & 8.99 & 8.36 & 1.48 & 3.5 & 6.54 & 6.27 & 7 & 6.73 \\
4.87 & 7.51 & 4.01 & 4.56 & 3.12 & 5.31 & 30.41 & 30.08 & 6 & 6.15 \\
2.73 & 2.61 & 5.08 & 6.75 & 6.51 & 8.17 & 44.17 & 48.73 & 6 & 5.37 \\
1.50 & 2.02 & 6.57 & 6.03 & 0.51 & 2.68 & 50.15 & 54.65 & 3 & 6.63 \\
1.56 & 0.99 & 3.22 & 4.25 & 9.99 & 12.17 & 39.71 & 35.69 & 6 & 7.65 \\
3.48 & 4.35 & 13.67 & 13.42 & 8.64 & 10.59 & 22.42 & 19.99 & 7 & 5.11 \\
1.78 & 1.42 & 10.51 & 10.22 & 3.93 & 5.88 & 7.00 & 7.09 & 7 & 6.37 \\
1.30 & 1.21 & 11.41 & 10.68 & 5.12 & 7.59 & 15.24 & 15.29 & 5 & 5.41 \\
1.35 & 1.76 & 6.12 & 5.88 & 4.61 & 6.51 & 0.46 & 0.56 & 6 & 6.79
\end{tabular}

M: Measured values

P: Predicted values 


\section{COMPARISON WITH AVAILABLE PUBLISHED MODELS}

The developed models of fatigue and rutting, which are considered the most important structural pavement failure, were compared with the available published models as follows and as shown in Figure 1, Figure 2, Figure 3 and Figure 4:

- $\quad$ Fatigue wet-non-freeze zone: model developed by Ker et al., 2007 [14] as shown in Table 1 versus the developed model of Equation (1). The comparison is shown in Figure 1.

- $\quad$ Fatigue dry-non-freeze zone: model developed by Ker et al., 2007 [14] as shown in Table 1 versus the developed model of Equation (2). The comparison is shown in Figure 2.

- Rut depth wet-non-freeze zone: model developed by Naiel, 2010 [6] as shown in Table 1 versus the developed model of Equation (9). The comparison is shown in Figure 3.

- Rut depth dry-non-freeze zone: model developed by Naiel, 2010 [6] as shown in Table 1 versus the developed model of Equation (10). The comparison is shown in Figure 4.

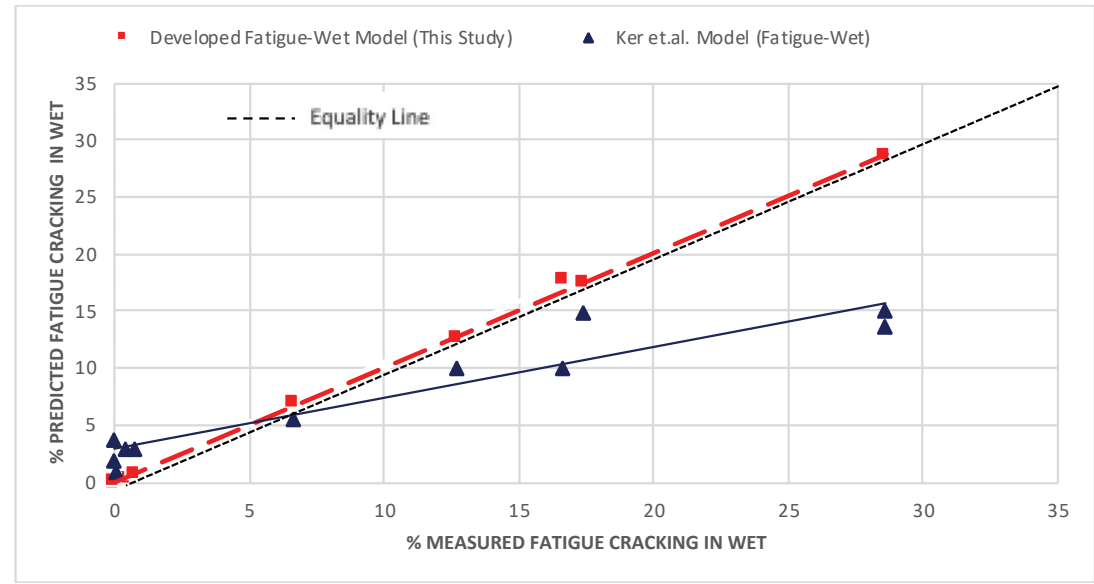

Figure 1 - Measured vs. Predicted Values using Different Fatigue-Wet Models

It can be clearly noticed that the developed models of fatigue and rutting in this study predict better than the available published models. The developed model of fatigue-wet generally overestimated the values; however, the Ker et al. model overestimated in case of \%fatigue less than $7 \%$ and underestimated when \%fatigue is more than $7 \%$. On the other hand, the developed model of fatigue-dry overestimated the values when $\%$ fatigue is less than $2 \%$ and underestimated over $2 \%$. However, the Ker et al. model overestimated when $\%$ fatigue is less than $3.5 \%$ and underestimated over $3.5 \%$.

For rut-wet model, the developed model in this study overestimated the rut depth when the depth is less than $11.5 \mathrm{~mm}$ and underestimated over this value. However, the model 
developed by Naiel overestimated the rut depth when the depth is less than $7.5 \mathrm{~mm}$. On the other hand, the developed model of rut-dry overestimated the rut depth in case of rut depth less than $6.5 \mathrm{~mm}$. However, the model by Naiel generally underestimated the values.

In conclusion, the average \% error of fatigue and rutting models developed in this study is 4 times less than the average \% error obtained from the available published models.

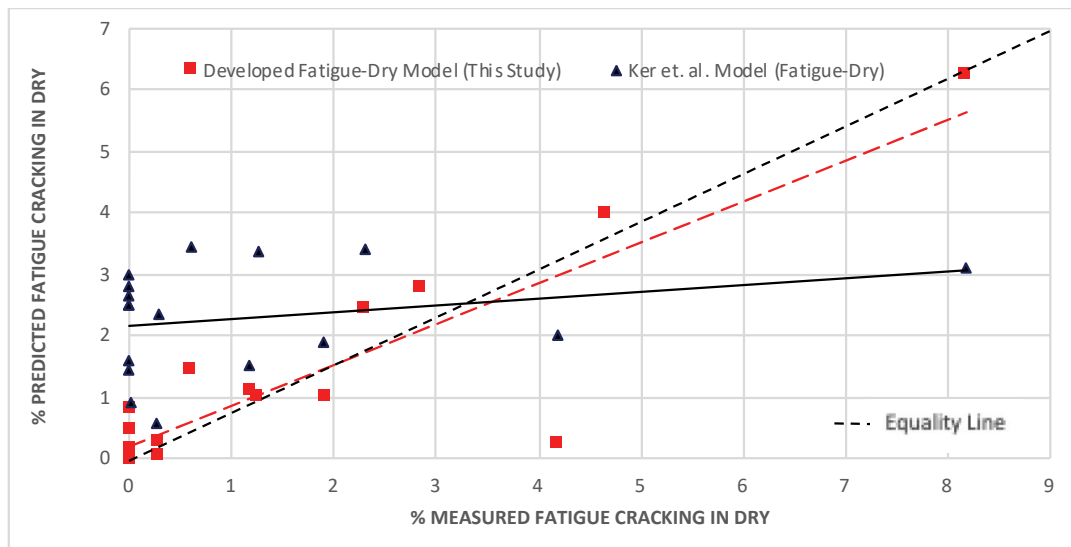

Figure 2 - Measured vs. Predicted Values using Different Fatigue-Dry Models

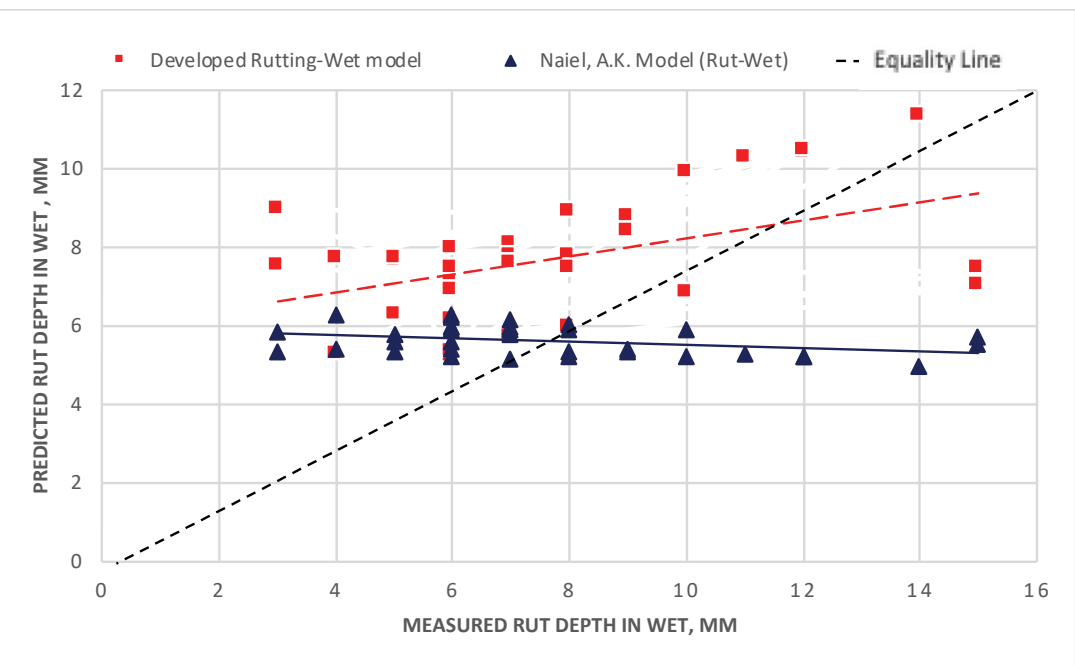

Figure 3 - Measured vs. Predicted Values using Different Rut-Wet Models 


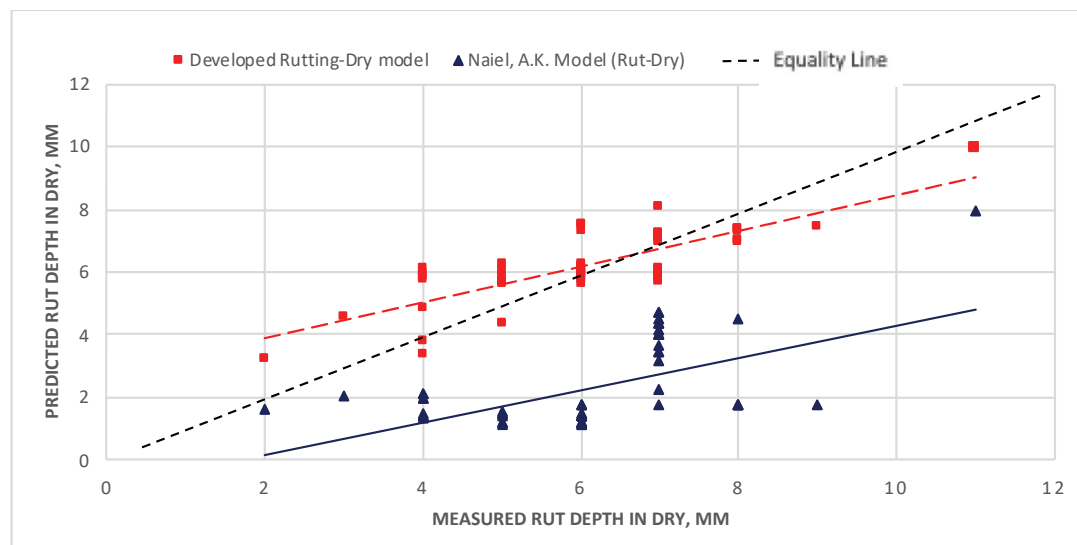

Figure 4 - Measured vs. Predicted Values using Different Rut-Dry Models

\section{CONCLUSIONS}

The main objective of this study is to develop pavement distress prediction models for main roads located in non-freeze climatic zones, which represent most of the Middle East countries, to be used in pavement management system. Six pavement distress prediction models were developed for fatigue cracking, longitudinal cracking, transverse cracking, raveling distress, bleeding distress and rut depth using data extracted from the Long-Term Pavement Performance (LTPP) program. It was found that pavement age factor is sensitive to most of the developed models while plasticity index and air temperature are very sensitive to fatigue cracking. Additionally, \%passing the \#200 sieve $(0.075 \mathrm{~mm})$ of subgrade soil is sensitive to longitudinal cracking, which indicates that too much fine aggregates in the mix could result longitudinal cracking. On the other hand, \%air void of asphalt layer is sensitive to bleeding distress. Validation process was performed using Long-Term Pavement Performance data sets different from the database used in the model development process. The results indicate that the predicted values are fairly close to the measured values at the corresponding LTPP sites. A comparison is also made between the developed models and the available published models for fatigue and rutting models, which are assumed the most important pavement distresses. This study is considered as a crucial attempt to develop such models for the Middle East region due to lack of resources led to unavailability of such models in most of the Middle East countries. However, calibration of the developed models is recommended based on local conditions of a country whenever the pavement performance data is available.

\section{FUTURE WORKS AND RECOMMENDATIONS}

The results of this study are very important to the Middle East countries experiencing similar climatic conditions. However, calibration of the developed models is recommended based on local conditions, whenever pavement performance data is available. Furthermore, elastic modulus of AC layer shall be considered as possible factor that could affect the developed 
models especially for fatigue, longitudinal, and transverse cracking. On the other hand, layer thickness and \% voids in mineral aggregate should also be considered as possible factors that could affect rut depth models.

\section{List of Abbreviations}

ESAL : Traffic loading represented by Equivalent Single Axle Load

$\mathrm{MCb} \quad$ : Moisture content of base/subbase courses

$\mathrm{Mr} \quad$ : Resilient modulus of subgrade soil

MCS : Moisture content of subgrade soil

P200 : \% Passing the \#200 sieve $(0.075 \mathrm{~mm})$ of subgrade soil

PA : Pavement age since overlay

$\mathrm{Pb} \quad: \%$ asphalt content in the mix

PI : Plasticity index of subgrade soil

$\mathrm{T} \quad$ : Asphalt pavement thickness

Ta : Air temperature

Va : \% Air voids of asphalt mix

\section{References}

[1] Haas, R., Hudson, R., Zaniewski, J., Modern Pavement Management. Krieger Publishing Company, Malabor Florida, 1994.

[2] Stantec-HPMA Manual, Highway Pavement Management Application (HPMA). User Documentation, V4.50. GARBLT Research Project in Egypt, Technical Consultations Bureau, Applied Engineering Technologies (TCB/AET), Cambridge, ON, Canada, 2001.

[3] George, K. P., Rajagopal, A.S., Lim, L. K., Models for Predicting Pavement Deterioration. Transportation Research Record 1215, 1-7, 1989.

[4] Li, N., Haas, R., Xie, W-C, Investigation of Relationship Between Deterministic and Probabilistic Prediction Models in Pavement Management. Transportation Research Record 1592, 70-79, 1997.

[5] Zimmerman, K. A., Testa, D. M., An Evaluation of Idaho Transportation Department Needs for Maintenance Management and Pavement Management Software Tools, 2008.

[6] Naiel, A. K., Flexible Pavement Rut Depth Modeling For Different Climate Zones. Ph.D. Thesis, Wayne State University, 2010. 
[7] Kulkarni R.B., Miller R.W., Pavement Management Systems Past, Present, and Future. Transportation Research Record 1853, 65-71, 2002.

[8] Li, N., Xie, W-C; Haas, R., Reliability-Based Processing of Markov Chains for Modeling Pavement Network Deterioration. Transportation Research Record 1524, 203-213, 1996.

[9] Porras-Alvarado, J. D., Probabilistic Approach to Modeling Pavement Performance using IRI Data. In Proceedings of 93rd Annual Meeting of the Transportation Research Board, Washington, DC, 2014.

[10] ARA Inc. Guide for Mechanistic-Empirical Design of New and Rehabilitated Pavement Structures. Final Documents, NCHRP, Champaign, 2004.

[11] Göransson, N. G., Den Svenska Nationella LTPP Database, VTI, 2009.

[12] Asphalt Institute, Research and Development of the Asphalt Institute's Thickness Design Manual (MS1), 9th Ed. Research Report: 82-2, 1982.

[13] Ali, H. A., Tayabji, S. D., Evaluation of Mechanistic-Empirical Performance Prediction Models for Flexible Pavement. Transportation Research Record, 1629, 169-180, 1989. http://Doi: 10.1016/j.sbspro.2012.06.1012.

[14] Ker, H., Lee, Y., Wu, P., Development of Fatigue Cracking Performance Prediction Models for Flexible Pavements Using LTPP Database. Transportation Research Board 86th Annual Meeting, Washington, D.C, January 21-25, 2007.

[15] George, K., Vepa, T., Shekhran, A., Prediction of Pavement Remaining Life. 1996.

[16] Ali, B., Numerical Model for the Mechanical Behavior of Pavement: Application to the Analysis of Rutting. Ph.D. Thesis, University of Science and Technology Lille, 2006.

[17] Federal Highway Administration (FHWA) 2002. Available from internet: https://www.fhwa.dot.gov/research/tfhrc/programs/infrastructure/pavements/ltpp/ (Accessed August 2017).

[18] Long-Term Pavement Performance (LTPP), 2017. Available from: https://infopave.fhwa.dot.gov/ (Accessed on September 19, 2017).

[19] Abo-Hashema, M. A., Sharaf, E. A., Development of Maintenance Decision Model for Flexible Pavements. International Journal of Pavement Engineering, 10 (3), 173-187, 2009.

[20] Shahin, M. Y., Kohn, S. D., Pavement Maintenance Management for Roads and Parking Lots. United States Army Corps of Engineers, Technical Report: M-294, 1981.

[21] This reference must be added to the list because it is cited in the manuscript on page 10. 